\title{
MONTHLY VARIATION OF WAVE SET-UP HEIGHT IN THE YONESHIRO RIVER MOUTH
}

\author{
Hitoshi Tanaka ${ }^{1}$, Hanako Nakura ${ }^{2}$ and Nguyen Xuan Tinh ${ }^{3}$
}

\begin{abstract}
It is known that in the coastal area facing the Sea of Japan, winter storm is very severe due to strong wind from Siberia and the wave height attains to $6-7 \mathrm{~m}$ during this period. Hence water level rise in a river entrance due to wave set-up may exceed $1 \mathrm{~m}$, which is considerably higher than average tidal amplitude in this region, $0.2-0.5 \mathrm{~m}$. However, due to much influence of complicated geographical processes on wave set-up height in a river mouth, quantitative investigations have hardly been done until now. In addition, the water level in a river mouth is complicatedly interacted among tidal motion, river discharge, ocean waves and so on, and hence it is difficult to make highly precise estimation. In this study, water level rise in the mouth of the Yoneshiro River in Akita Prefecture, Japan is investigated. Geographical features of the river mouth are greatly dependent on seasonal variation of major physical forces. Therefore, the characteristic of wave set-up is assumed to be different according to the season, and hence monthly variation of wave set-up is quantified. It is found in winter, the water level rise by wave set-up becomes approximately $10 \%$ of the deep water wave height, whereas this ratio decreases rapidly in summer due to flushing of sediment around the river mouth caused by frequent occurrence of floods.
\end{abstract}

Keywords: wave set-up, water level rise, river entrance, breaking wave, Yoneshiro River mouth

\section{INTRODUCTION}

It is understood that the tide on the Japan Sea side gives comparatively less influence than that on the Pacific Ocean side, because it is ranged approximately $0.2-0.5 \mathrm{~m}$ on Japan Sea side while $1-2 \mathrm{~m}$ on the Pacific Ocean side. This difference is owing to internal bay characteristic on the Japan Sea side. In winter season, the northwest wind originated from the Siberian high atmospheric pressure causes very frequent severe storms in the Japan Sea. It is estimated that in case of deep water waves with $6-7 \mathrm{~m}$ height, wave set-up by wave breaking attains over $1 \mathrm{~m}$, which is considerably higher than the average tidal range on the Japan sea side. However, very little quantitative investigation has been done in this regard until now, although it is of practical importance to make precise estimation of water level rise in an individual river mouth in connection with flood control and salinity intrusion. One of the difficulties is the water level in a river mouth is complicatedly interacted among tide, discharge, ocean waves and so on. Another difficulty is acquisition of accurate field data on both sea and river sides which enables precise estimation of water level rise in a river above sea level.

There are several researchers studied on the empirical water level rise at river entrance such as Hanslow et al. (1992, 1996), Tanaka et al. (2000, 2003, 2008), Dunn (2001), Oshiyama et al. (2001), Shuttleworth et al. (2005) and Malhadas et al. (2009). Among them, Hanslow et al. (1992) have conducted a very detailed measurement of wave set-up at the entrance of Brunswick Heads on the north coast of New South Wales in Australia. The obtained wave set-up was less than 3\% of deep water wave height while the maximum of wave height was up to $3 \mathrm{~m}$, and average water depth at entrance was smaller than 4m. Dunn (2001) has further compared the water level data in Brunswick with nearby tidal gauge and confirmed the same conclusion. In contrast, Tanaka et al. (2000) and Oshiyama et al. (2001) have found that the wave set-up in the Nanakita and Natsui rivers are attained in a range from 10 to 20 percent of offshore wave height, respectively. The difference between these studies is because the occurrence of wave set-up has distinct dependence on river entrance morphology and the magnitude of the storm.

In this research, water level variation in the river mouth of the Yoneshiro River, classified as class A river, in Akita Prefecture, Japan is investigated. Geographical features in the mouth of a river are greatly changed by the season reflecting different predominant forcings. It is thus plausible to assume that the characteristic of wave set-up is different according to the season in a year. Therefore, wave setup height in the Yoneshiro River mouth is quantified on a monthly basis.

\footnotetext{
${ }^{1}$ Department of Civil Engineering, Tohoku University, 6-6-06 Aoba Sendai 980-8579, Japan.

${ }^{2}$ Department of Civil Engineering, Tohoku University, 6-6-06 Aoba Sendai 980-8579, Japan.

${ }^{3}$ Department of Civil Engineering, Tohoku University, 6-6-06 Aoba Sendai 980-8579, Japan.
} 


\section{STUDY AREA}

Study area of this study is focused on the Yoneshiro River which located in the Akita Prefecture in Japan as seen in Fig. 1. According to the Japan river classification standard, the Yoneshiro River belongs to a class A river and flows into the Japan Sea. Its catchment area is of $4,100 \mathrm{~km}^{2}$ and the length of $136 \mathrm{~km}$. With respect to the river catchment area, it is 14th largest in nationwide and is ranked 5th largest in the Tohoku District. The bed material at the river mouth mainly consists of sands and gravels, and the average diameter of the material is $1.25 \mathrm{~mm}$.

In general for the coastal areas facing the Japan Sea, it is impacted by two different main extreme phenomena, one is large waves caused by the strong wind from the Siberia high atmospheric pressure during winter season and another is flood occurrence in spring and summer by snow melting and by typhoons, respectively (see Figs. 2, 3).

There exists a long sand spit at the northern part of the Yonoshiro River mouth as seen in Fig.1 and its morphology changes are closely corresponding to the above two severe events. Photo 1 shows the aerial photographs of morphology change at the Yoneshiro River mouth in 2007 and 2008. The high waves together with less river discharge from the river during winter make the sand spit particularly develop as seen in Photos 1(b), (c) and (d). The river mouth was almost closed in this season and the water depth at mouth was remained shallow. On the contrary, Photos 1(e) and (f) show the river mouth morphology immediately after the occurrence of flood, which has caused flushing of the sand spit to the sea side.

The tidal area extends up to approximately $6 \mathrm{~km}$ upstream from the river mouth, and the average of the maximum tidal range in the river mouth is $0.474 \mathrm{~m}$.

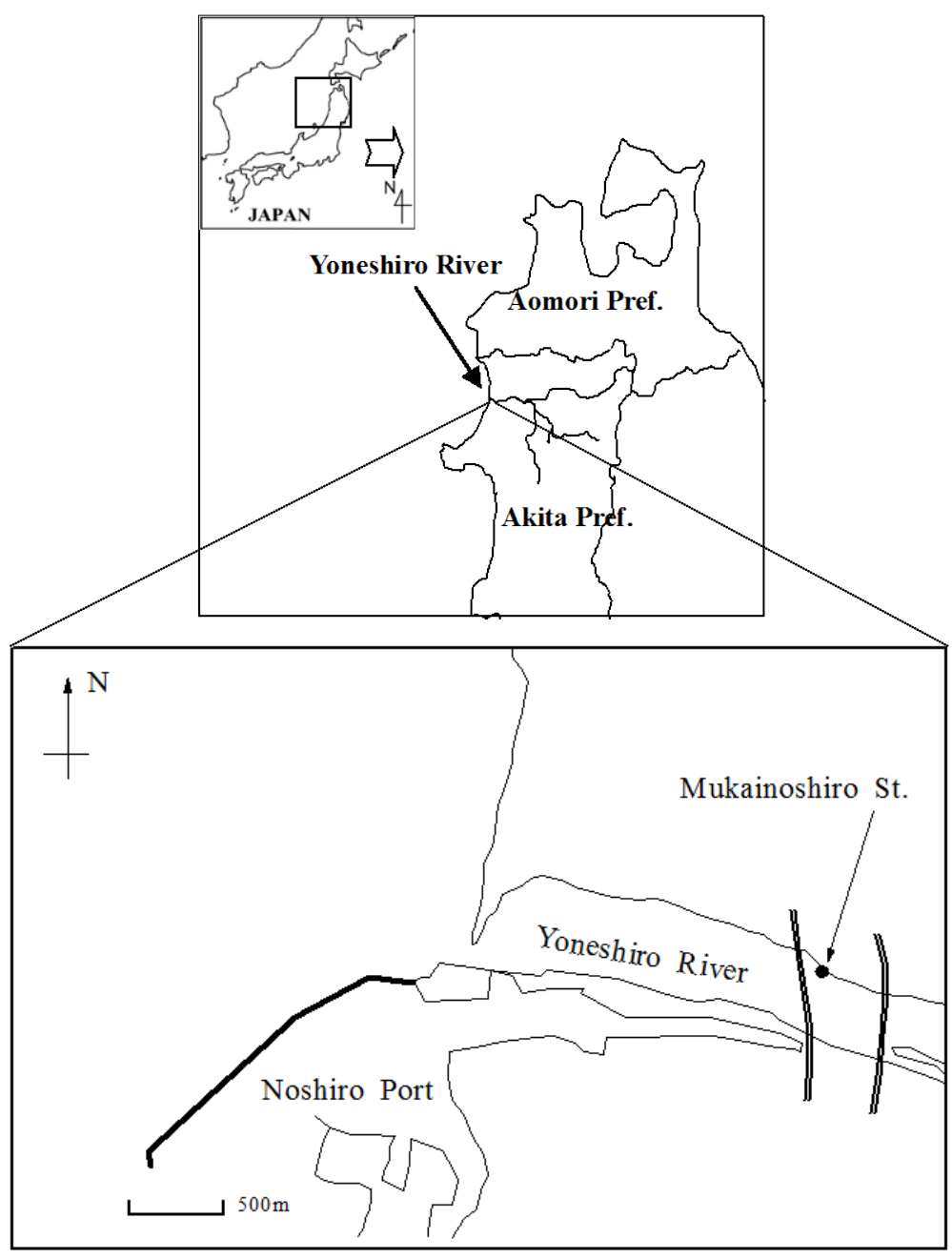

Fig. 1 Map of the Yoneshiro River mouth 


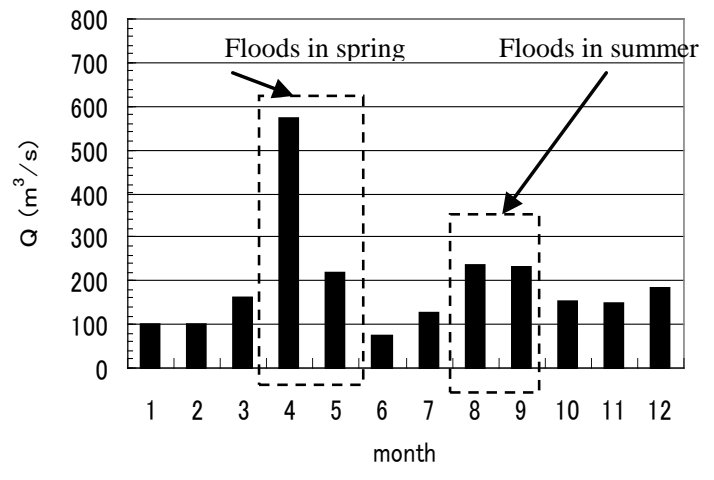

(a) 2003

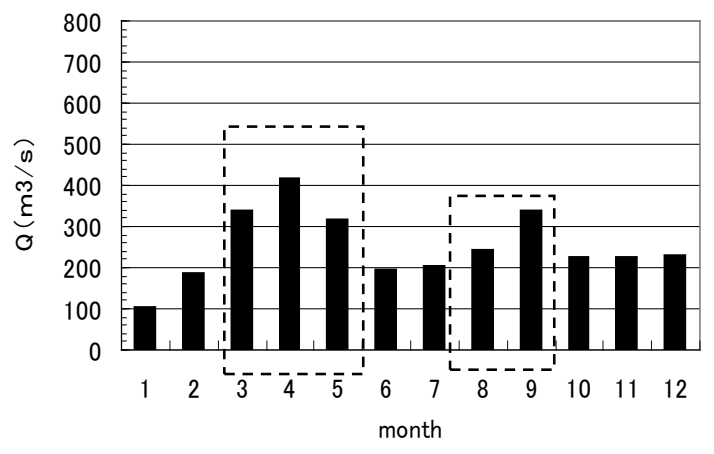

(b) 2004

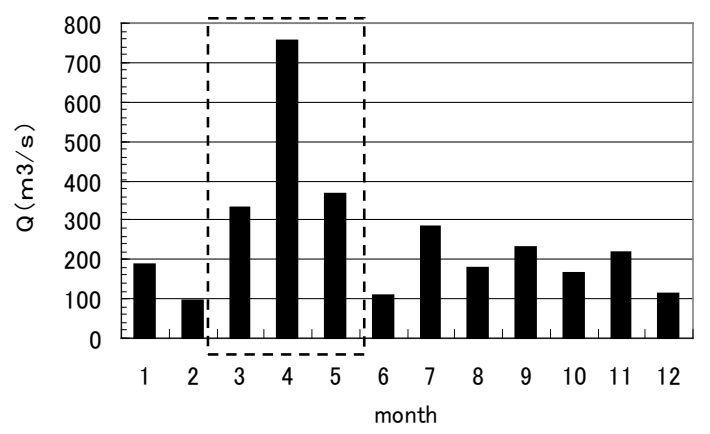

(c) 2005

Fig. 2 Monthly averaged discharge of Yoneshiro River

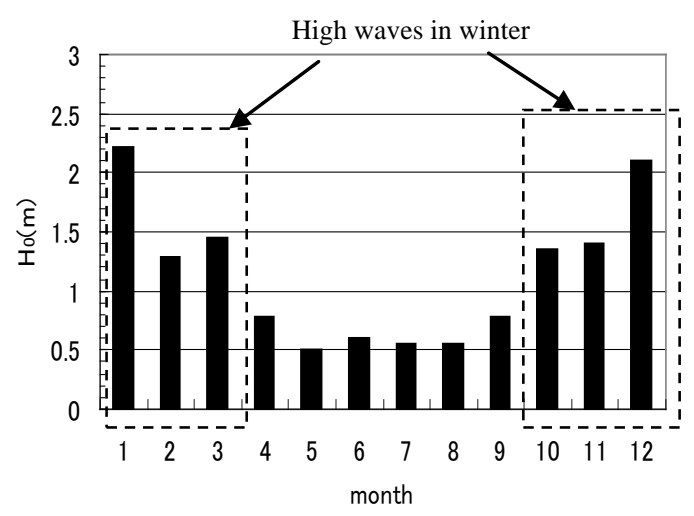

(a) 2003

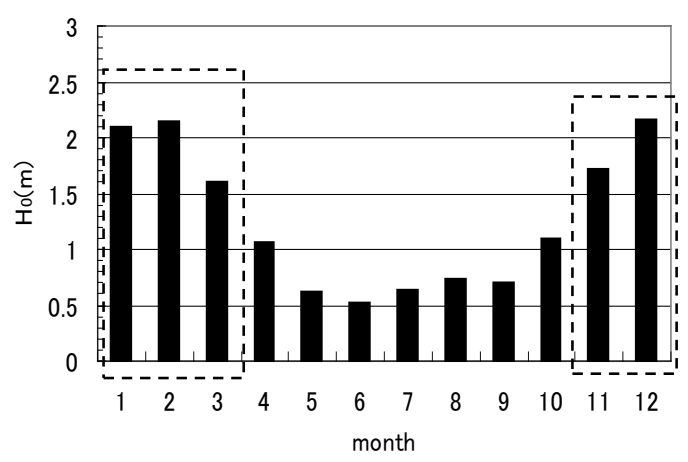

(b) 2004

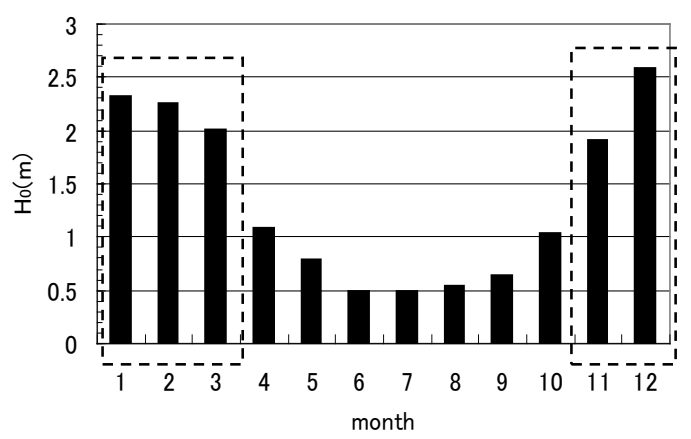

(c) 2005

Fig. 3 Monthly averaged offshore wave height 


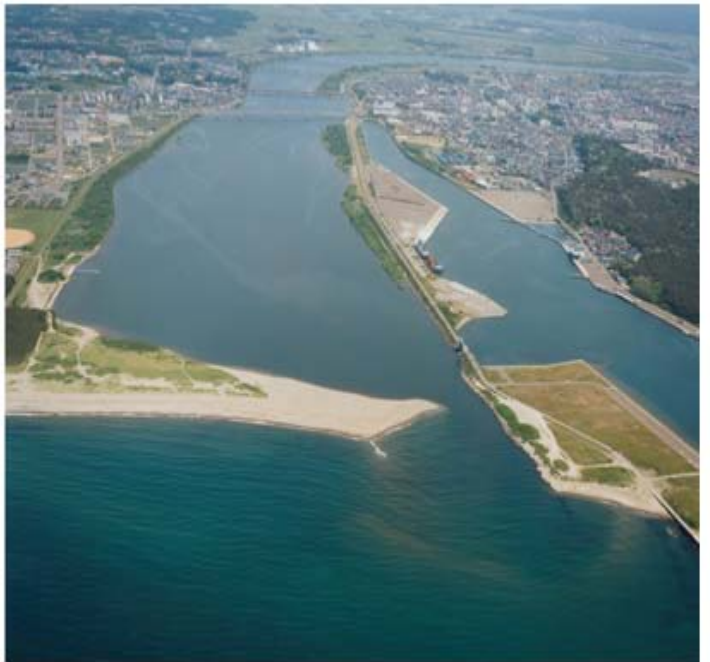

(a) June 13, 2007

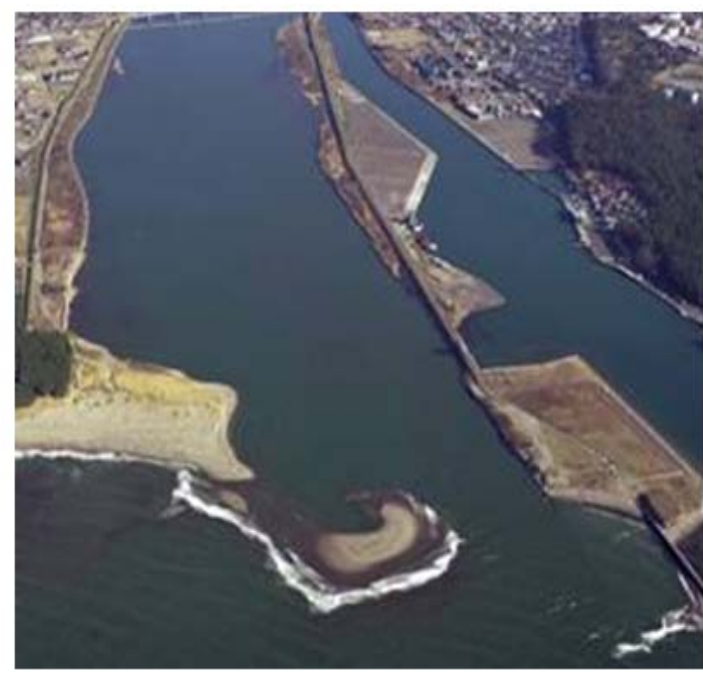

(c) October 29, 2007

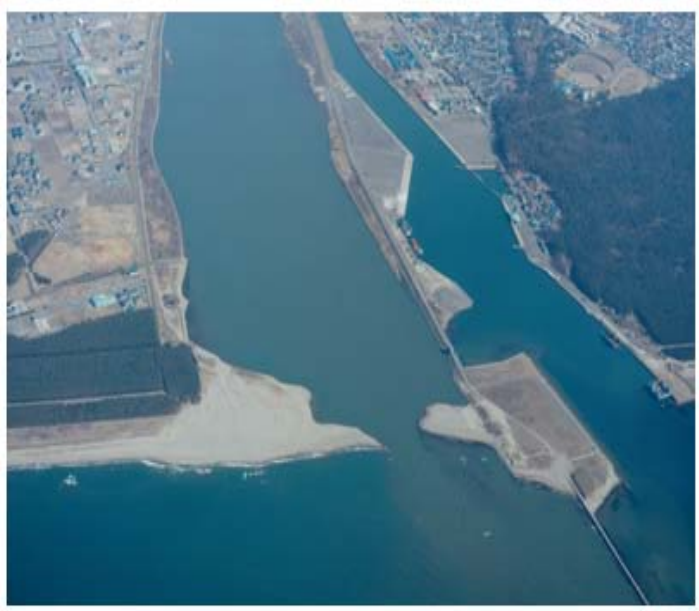

(e) March 21, 2008

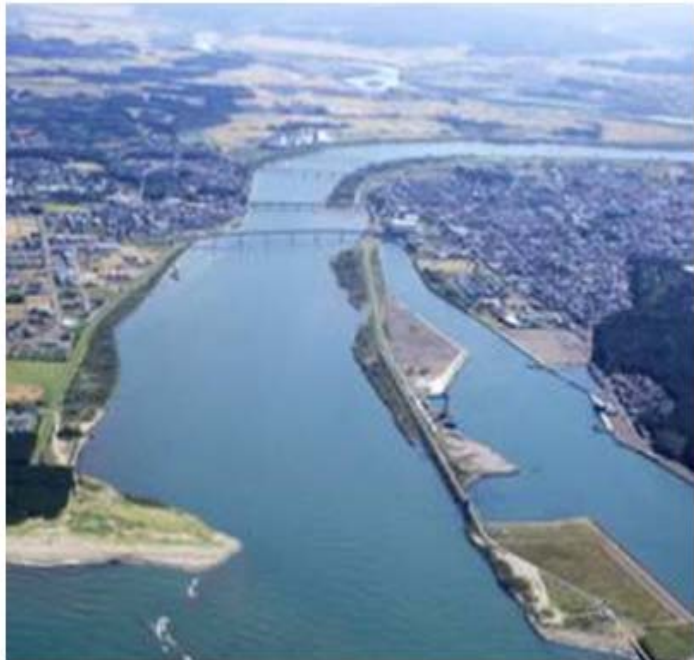

(b) October 2, 2007

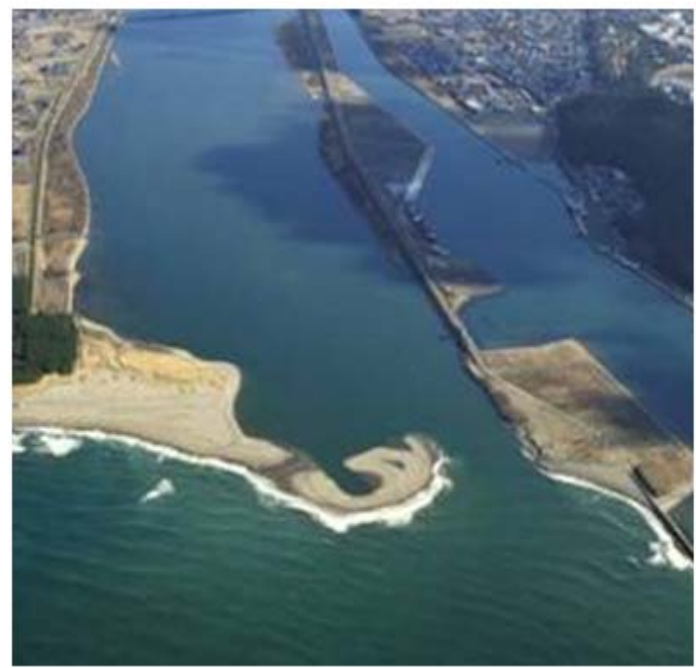

(d) December 22, 2007

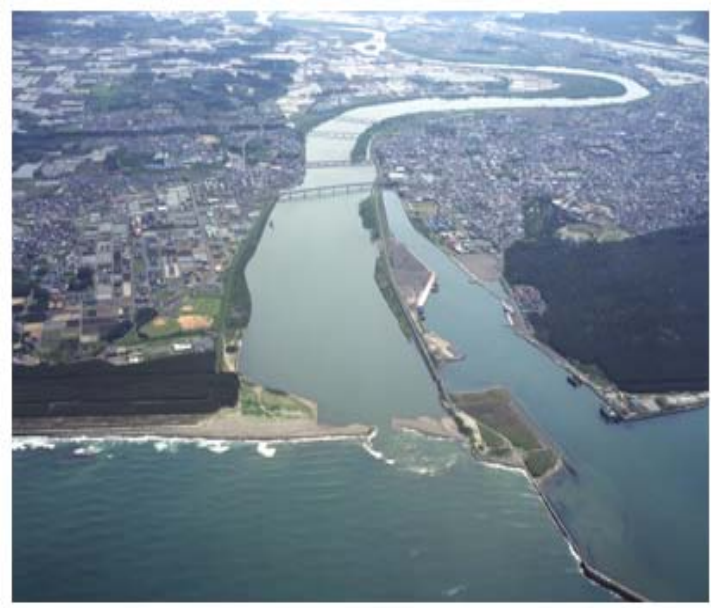

(f) May 8, 2008

Photo 1 Morphology change at the Yoneshiro River mouth 


\section{DATA SET}

In order to achieve the above objectives, the required data sets are a time series of the wave height in deep water, water level at some distance upstream of river, and tidal level, as well as the river discharge during the event.

The wave set-up is the height of Mean Water Level (MWL) above Still Water Level (SWL). In most of cases, the estimation of wave set-up at a river mouth has been based on water levels measured some distance upstream from the river mouth and then compared with a measured tidal level where wave effects can be neglected (Tanaka et al., 2000). However, the water level rise at a river entrance is not only caused by wave breaking but also by the wind set-up and suction effects due to storm. In order to eliminate these influences the closest tide station was chosen to compare with the measured water level in the river, assuming the both water levels are equally affected by the wind set-up and suction impacts.

To evaluate water level rise due to wave breaking in the Yoneshiro River mouth, measured data at the Mukainoshiro Station, which is located in $1.8 \mathrm{~km}$ upstream from the river mouth as shown in Fig. 1 and the Photo 2, is used. The difference from tidal elevation at the Fukaura Port is calculated. Although the distance between the Yoneshiro River mouth and Fukaura Port is $57.4 \mathrm{~km}$, it is assumed that both wind set-up effect due to strong wind and suction effect due to low pressure appear equally at these two measuring stations, and that the difference of the water level at these stations is attributed to wave set-up effect. Thus, the water level rise in the river mouth can be estimated by

$$
\Delta \eta=\eta_{R}-\eta_{T}
$$

where $\eta_{R}$ is the water level in the Yoneshiro River mouth, and $\eta_{T}$ is the tidal elevation at the Fukaura Port.

In addition, river discharge and wave data are collected from the Futatsui Station and Fukaura Port, respectively to judge whether water level rise is induced by backwater effect or wave set-up.

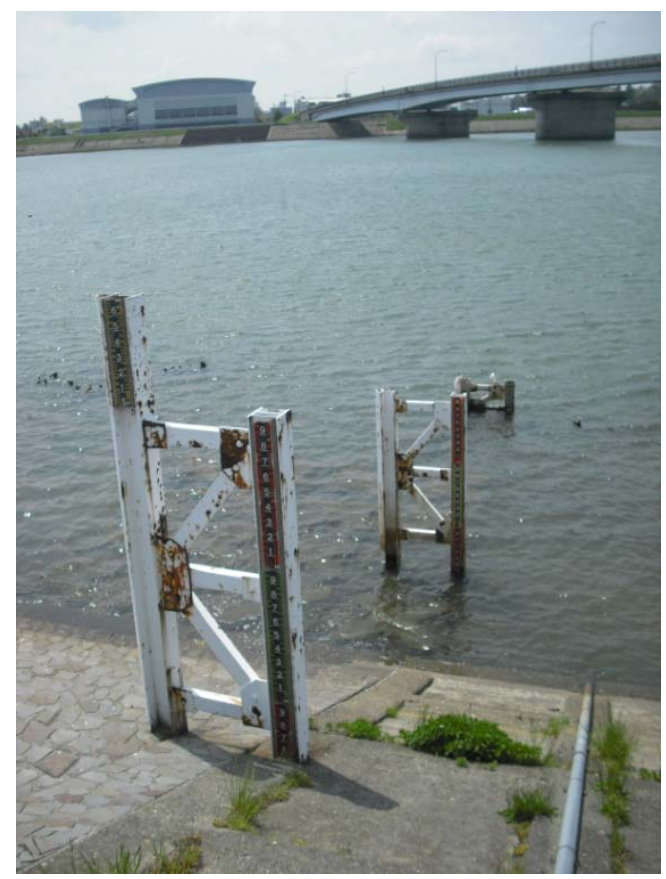

Photo 2 Water level measuring station at the river mouth (Mukainoshiro Station)

\section{DATA ANALYSIS AND RESULTS}

\section{Data Selection}

In general, water level in a river mouth is complicatedly affected by combined effects of tidal motion, river discharge and ocean waves. In order to investigate water level rise in a river entrance due to wave set-up, data set should be carefully selected to eliminate water level rise induced by river 
discharge especially during flood events. In this study, therefore, periods with low fresh water discharge under high wave condition are selected. The observed discharge data from March 2003 to February 2005 at the Futatsui Station in 2004 is shown in Fig. 4. From this measurement, three possible periods are selected which satisfies the above condition: Period A from January to February 2004, Period B from May to June 2005, and Period C from November to December 2004.

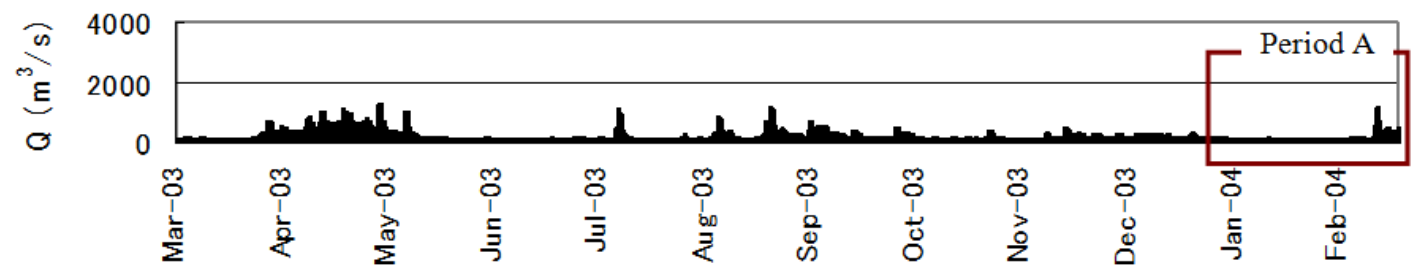

(a) from March 2003 to Feb 2004

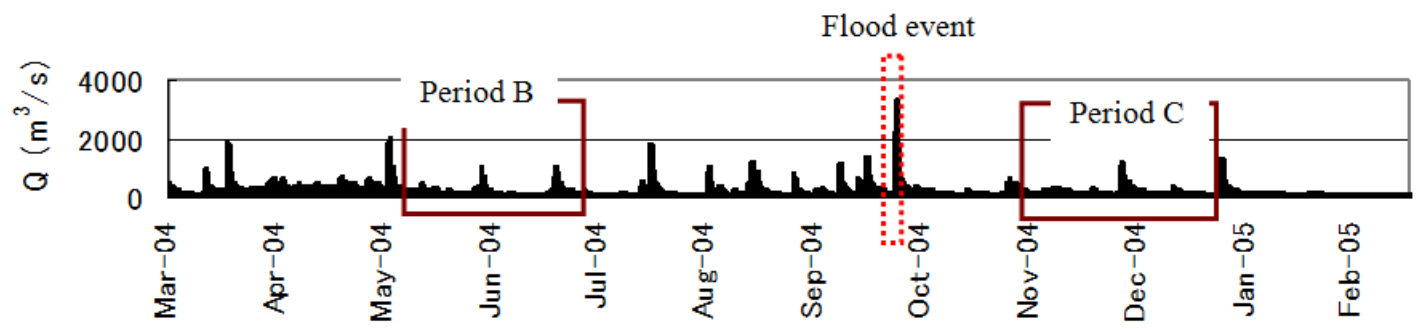

(b) from March 2004 to Feb 2005

Fig. 4 River discharge at Futatsui Station from March 2003 to Feb 2005

\section{Water Level Rise}

Figures 5, 6 and 7 illustrate the details of measurement water level, water level rise, river discharge and deep water wave height for each period. It is noted that especially during Period A and Period C, the river discharge was negligibly small, while waves were relatively higher. It is seen during these two periods that the water level rise, $\Delta \eta$, appears in phase with high waves. During Period B, on the contrary, both discharge and wave height do not show any distinct increase, and almost no water level rise can be observed.

From these results, it is concluded that water level rise in the river mouth during Period A and Period B is induced by wave set-up due to wave breaking.

Relationship between wave set-up height and wave height

In the nearshore area, wave breaking occurs and wave height decrease gradually in the onshore direction. As a result, the averaged sea level rises toward the shoreline. The wave set-up height on the shoreline can be generally expressed as a function of wave height (Battjes and Janssen, 1978; Bowen et al., 1968; Goda, 1975; Guza and Thornton, 1981). Similarly, wave set-up height in a river entrance can be assumed to be proportional to the deep water wave height as follows (Hanslow and Nielsen, 1992; Hanslow et al., 1996, and Tanaka et al., 2008).

$$
\Delta \eta=a H_{0}
$$

where $\Delta \eta$ is the wave set-up height at the river entrance, $H_{0}$ : the deep water wave height, and $a$ is the constant obtained from regression analysis. 

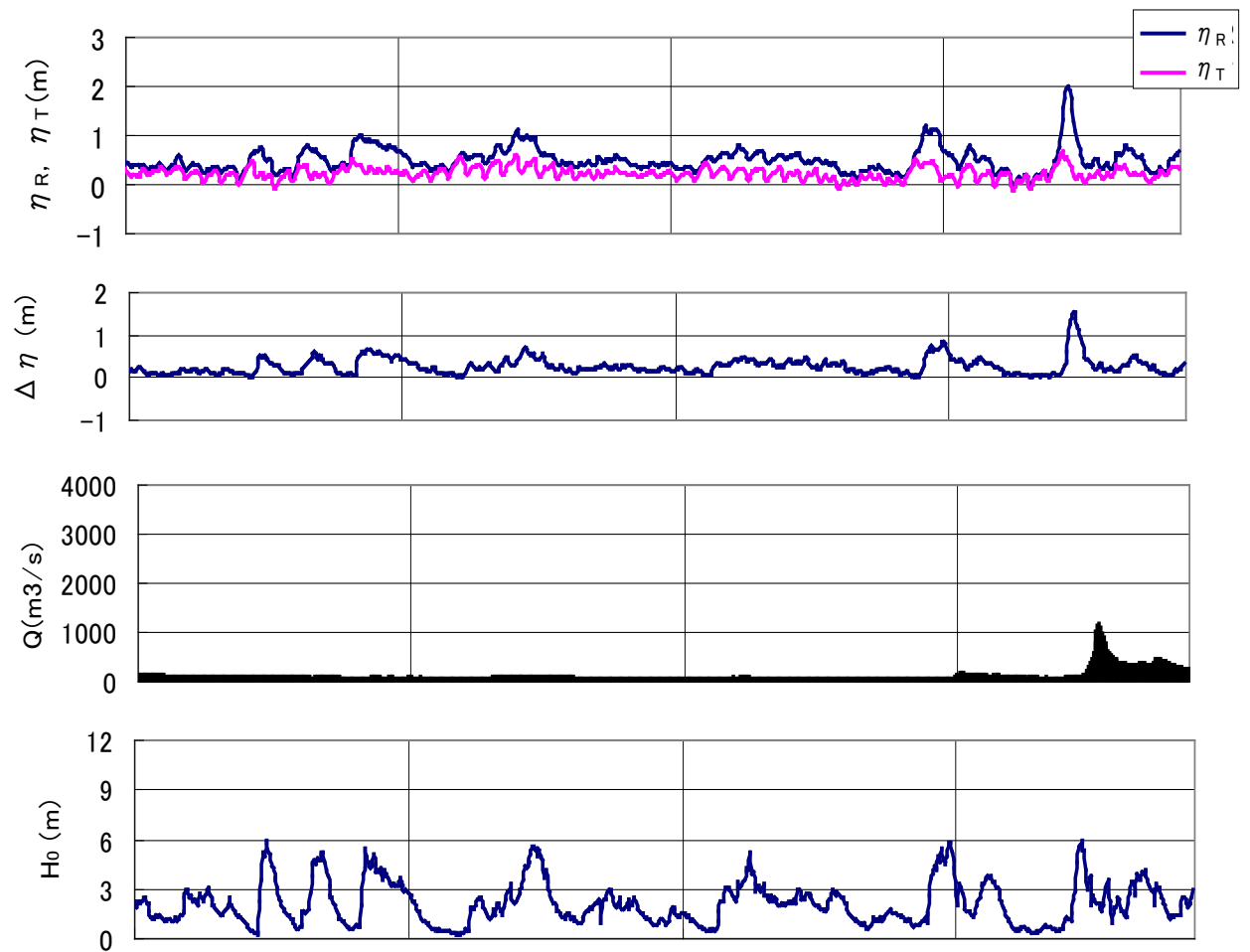

Jan. 2004

Feb. 2004

Fig. 5 Time-variation of water level, water level rise, discharge, and wave height during Period A
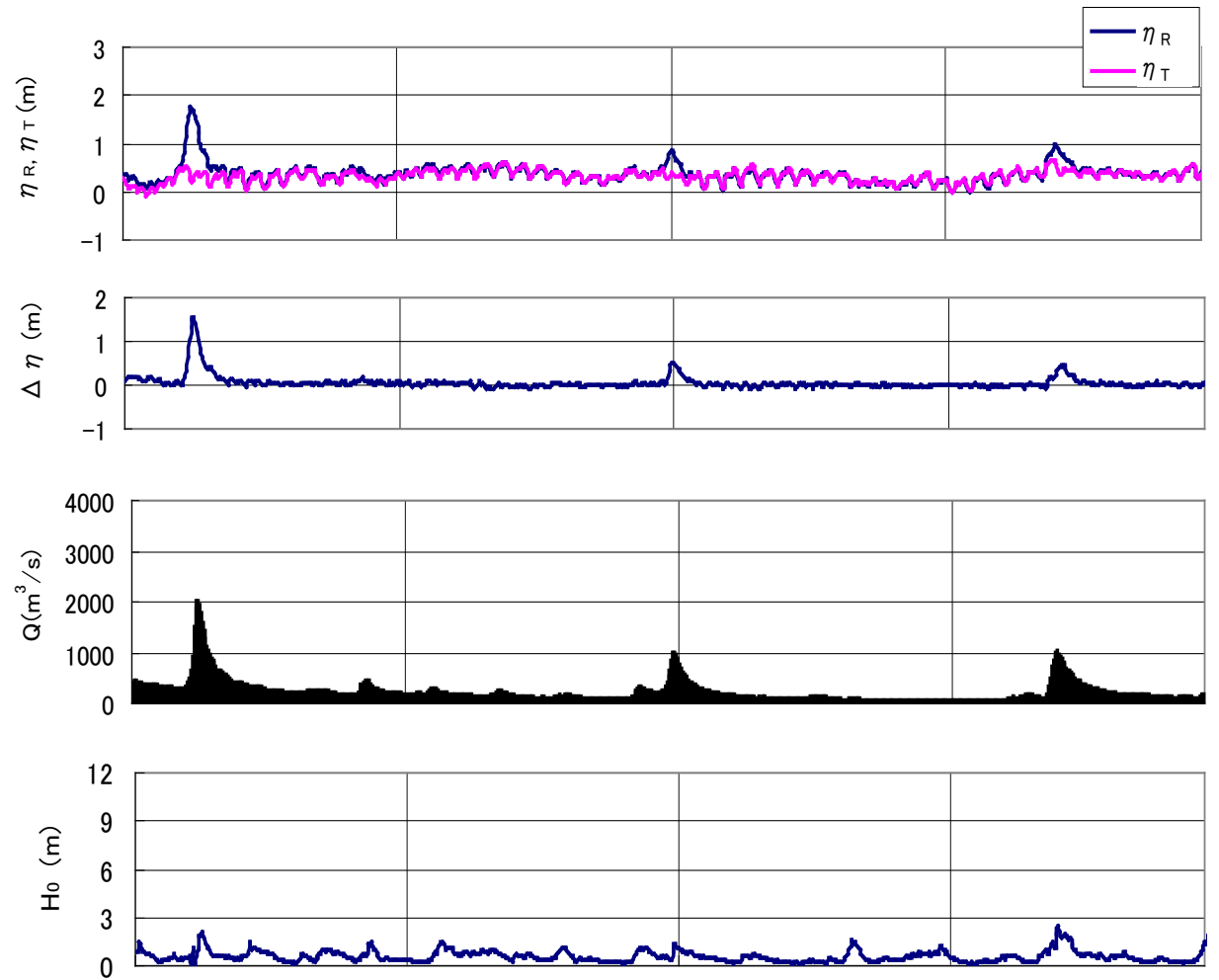

May 2004

June 2004

Fig. 6 Time-variation of water level, water level rise, discharge, and wave height during Period B 

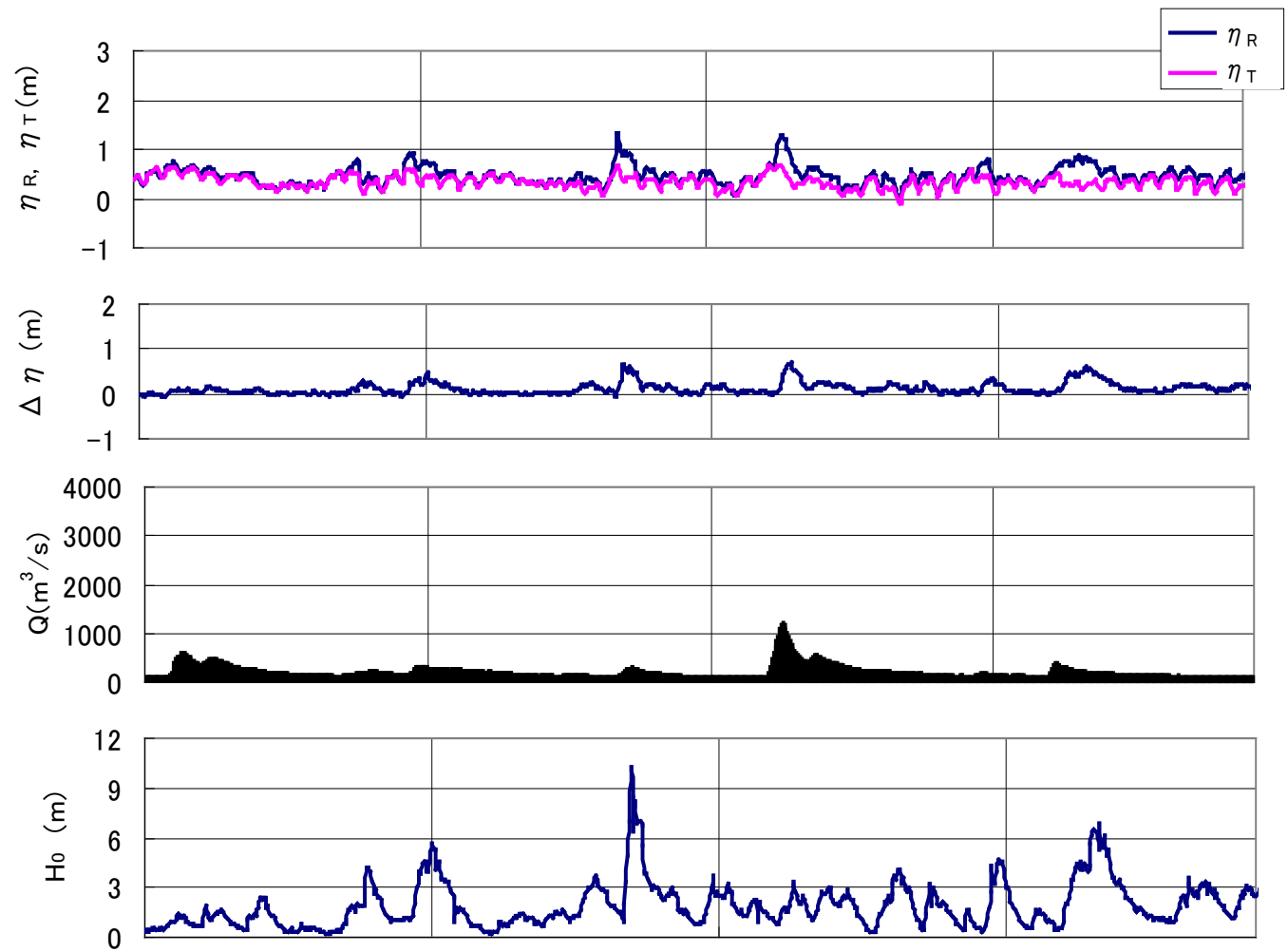

Nov. 2004

Dec. 2004

Fig. 7 Time-variation of water level, water level rise, discharge, and wave height during Period C

The relationship between the water level rise and the wave height for each period is illustrated in Figs. 8, 9 and 10. In Figs.8 and 10, linear correlation can be seen between $\Delta \eta$ and $H_{0}$, and the range of coefficient $a$ defined by Eq. (2) is from 0.07 to 0.12 . In contrast to these periods, the result during Period B in Fig.9 shows almost no correlation between these two quantities.

Figure 11 shows monthly variation of the coefficient $a$ in winter season from November 2003 to February 2005. It is found that this coefficient increases gradually with the passage of time. Moreover, distinct difference of the behavior of $a$ can be seen between the year of 2003 and 2004.

Tanaka et al. (2008) analyzed wave set-up height at different river entrance morphologies facing the Pacific Ocean in Japan, and concluded that the wave set-up height is inversely proportional to the average water depth at river mouth. From the result in Fig. 11, it might be concluded that the monthly variation of the coefficient reflects gradual decrease of the water depth caused by sediment intrusion due to winter storms. The difference of the coefficient between 2003 and 2004 can be attributed to a flood event in September 2004 (see Fig. 4). Typhoon No.21 caused flood discharge as high as $3,370 \mathrm{~m}^{3} / \mathrm{s}$ at Futatsui Station, and the water level exceeded the warning level. This flood along with other frequent events seen in Fig. 4 might have caused sand flushing, resulting in smaller water level rise in the year of 2004 . 


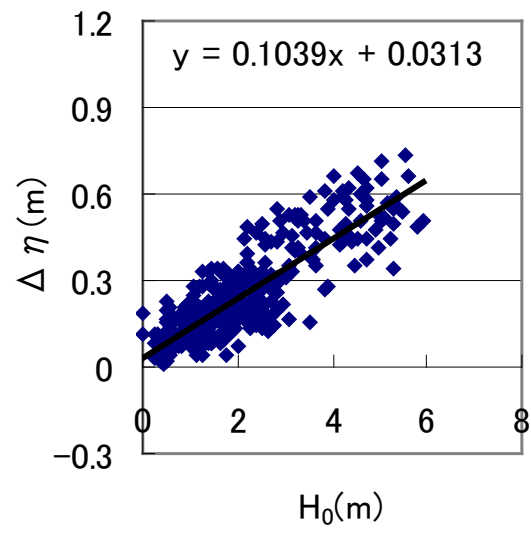

Jan 2004

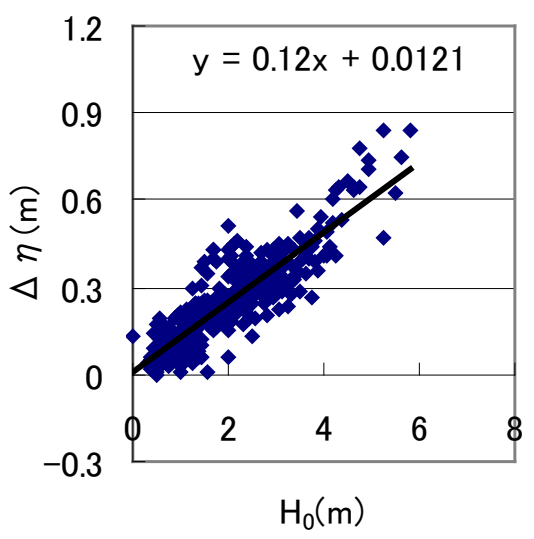

Feb 2004

Fig. 8 Relationship between wave set-up height and wave height (Period A).

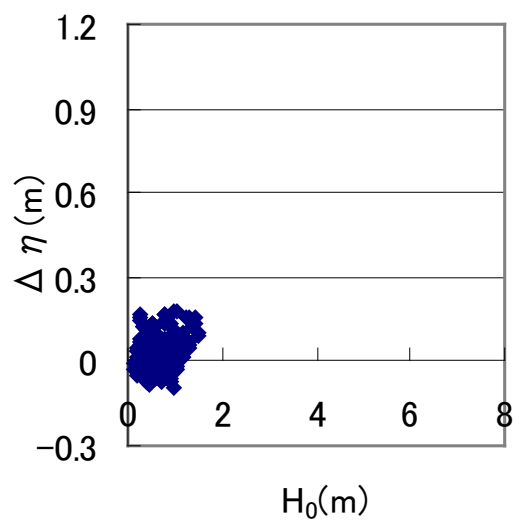

May 2004

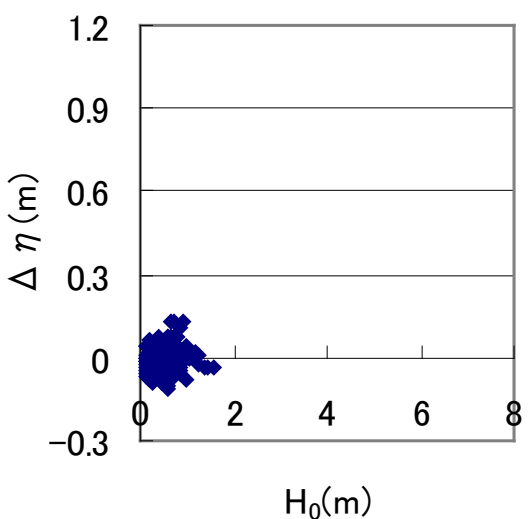

Jun 2004

Fig. 9 Relationship between wave set-up height and wave height (Period B).

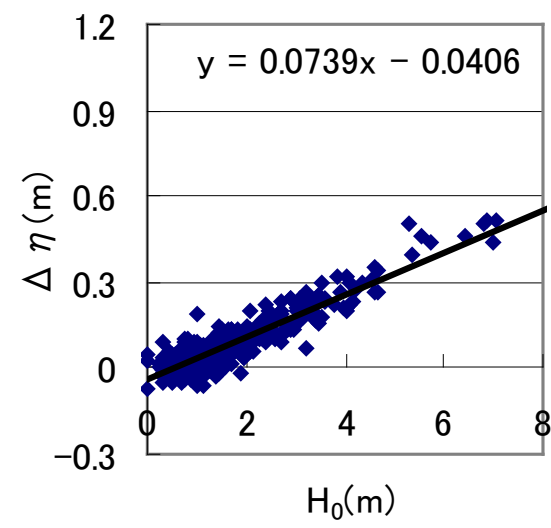

Nov 2004

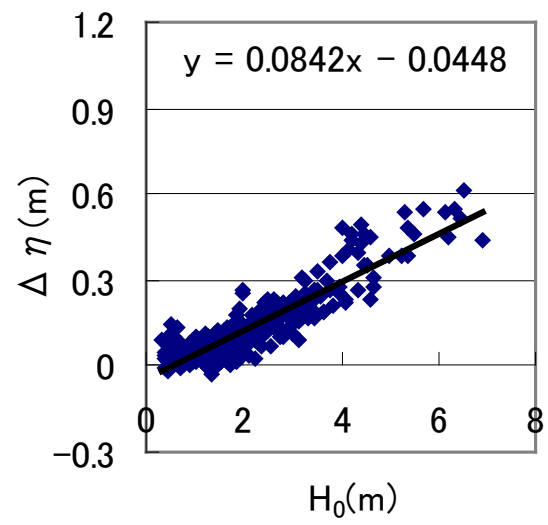

Dec 2004

Fig. 10 Relationship between wave set-up height and wave height (Period C). 


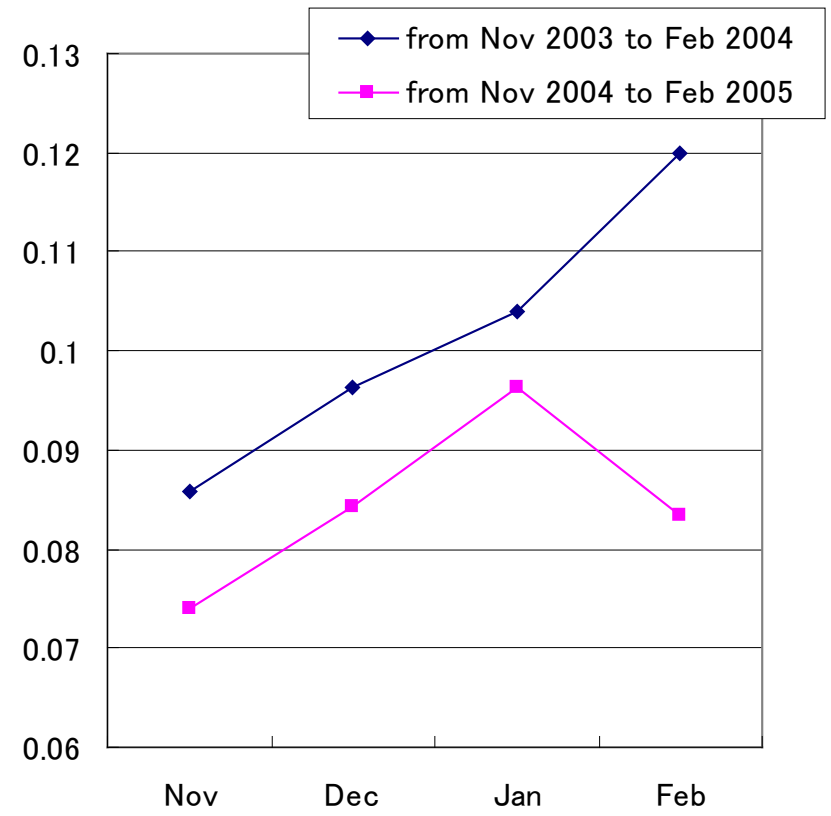

Fig. 11 Monthly variation of the regression constant a in Eq. (2)

\section{CONCLUSIONS}

It is found that water level rise by wave set-up in the Yoneshiro River mouth in winter is approximately $10 \%$ of the deep water wave height at the maximum. However, this constant of proportionality is slightly lower in a year when frequent flood events occurred in summer and autumn. This might be due to more sediment flushing out due to frequent floods, causing less influence of wave breaking.

\section{ACKNOWLEDGMENTS}

The authors wish to express their grateful thanks to Noshiro Office of River and National Highway, Ministry of Land Infrastructure and Transport, Japan, for their kind offer of the field data. This study was financially supported by Grant-in-Aid for Scientific Research from JSPS (No.21360230 and No.2109287), and also by Grant for "Academic Frontier Project" from the Ministry of Education, Culture, Sports, and Technology. The authors would like to gratefully appreciate these financial supports.

\section{REFERENCES}

Battjes, J.A., and J.P.F.M. Janssen. 1978. Energy loss and set-up due to breaking of random waves, Proceedings of 16th International Conference on Coastal Engineering, ASCE, 569-587.

Bowen, A.J., D.L. Inman, and V.P. Simmons. 1968. Wave setdown and setup, Journal Geophysical Research, 73, 8, 2569-2577.

Dunn, S. L. 2001. Wave setup in river entrances. Doctor Thesis in Department of Civil Engineering, University of Queensland, Brisbane, Australia, 191pp.

Goda, Y. 1975. Irregular wave deformation in the surf zone, Coastal Engineering in Japan, 18, 13-25, 1975.

Guza, R.T., and E.B. Thornton. 1981. Wave set-up on a natural beach, Journal Geophysical Research, 86, C5, 4133-4137.

Hanslow, D.J., and P. Nielsen. 1992. Wave setup on beaches and in river entrances, Proceedings of 23rd International Conference on Coastal Engineering, ASCE, 240-252.

Hanslow, D.J., P. Nielsen, and K. Hibbert. 1996. Wave setup at river entrance, Proceedings of 25th International Conference on Coastal Engineering, ASCE, 2244-2257.

Malhadas, S.M., P.C. Leitao, A. Silva, and R. Neves. 2009. Effect of coastal waves on sea level in Obidos Lagoon, Portugal, Continental Shelf Research, 29, 1240-1250. 
Oshiyama, S., H.S. Lee and H. Tanaka. 2001. Water level variation at a mouth of small to medium scale river, Annual Journal of Coastal Engineering, JSCE, 48, 411-415. (in Japanese)

Shuttleworth, B., A. Woidt, T. Paparella, S. Herbig, D. Walker. 2005. The dynamic behaviour of a river-dominated tidal inlet, River Murray, Australia, Estuarine, Coastal and Shelf Science, 64, 645-657.

Tanaka, H., H. Nagabayashi and K. Yamauchi. 2000. Observation of wave set-up height in a river mouth, Proceedings of 27th International Conference on Coastal Engineering, ASCE, 3458-3471.

Tanaka, H. and H.S. Lee. 2003. Influence of jetty construction on morphology and wave set-up at a river mouth, Coastal Engineering Journal, 45, 4, 659-683.

Tanaka, H. and X.T. Nguyen, and H. Nagabayashi. 2008. Wave setup at different river entrance morphologies, Proceedings of 31st International Conference on Coastal Engineering, ASCE, 975985. 